\title{
Success Factors for Creating Spin-Out Companies by South African Publicly Financed Research and Development Institutions: A Resource-Based View Perspective
}

\author{
P. Langa, E.I Edoun, V. Naidoo \\ Tshwane University of Technology, South Africa \\ eddiephumuza@gmail.com, edounsen@hotmail.com,naidoov@tut.ac.za
}

\begin{abstract}
Technology commercialisation using spin-out companies has shown to be a viable option by publicly financed research and development (R\&D) institutions internationally. In South Africa (SA) this trend of spin-out company creation for technology commercialisation is anticipated to be on the rise since the inception of the Intellectual Property Rights from Publicly Financed Research and Development Act number 51 of 2008 (IPR-PFRD Act). This study aimed at trying to understand the factors that influence the successful creation of spin-out companies by SA publicly financed R\&D institutions, utilising the RBV as the main theoretical framework. A survey questionnaire was distributed using a purposive sample approach to 49 key individuals (technology transfer professionals) who have been involved in spin-out creation in the past and the response was received from 17 respondents. A mixed methods research methodology was utilised and the data was presented using descriptive statistics and narration. The results of the data indicate a similar pattern to international trends and in some instances unique resource combinations that are relevant to SA.
\end{abstract}

Keywords: Technology commercialisation, Spin-out companies, Research \& Development Institutions, Resources Based view, Intellectual Property Right

\section{Introduction}

Several studies have been conducted to look at factors that influence the successful creation of spin-out companies emanating from universities (Di Gregorio \& Shane 2003; Powers \& McDougall, 2005; Gómez-Gras et al., 2006; Lockett, Wright and Franklin, 2003; Landry, Amara, Rherrad, 2006; Renault et al., 2016). These studies have looked at the factors that influence spin-out company creation by universities by looking at various factors from a resource base view perspective (RBV). The observation made from the studies mentioned above, is that they are largely focused on university-based spin-out companies and more on the international perspective. The important gap is that little research has been done on understanding spin-out companies within the South African context. The aim of this study was to investigate the success factors for creating spin-out companies by publicly-financed Research and Development (R\&D) in South Africa (SA) with a view of determining which are considered the most important. The study was undertaken with the objective of analysing the factors that play a role in the successful spin-out company creation process in a structured manner. The sub-objectives being: identifying the factors of importance in the spin-out creation process, categorising the factors identified and assessing the factors' role in spin-out company creation. The theoretical framework being the resource-based view. The objectives of the Intellectual Property Rights from Publicly Financed Research and Development Act number 51 of 2008 are to make provision that intellectual property (IP) emanating from publicly financed.

Research and development are identified, protected, utilised and commercialised for the benefit of the people of the Republic. It further states that publicly-funded research institutions must within 12 months of the coming into effect of the Act- (a) establish and maintain an office of technology transfer (OTT); or (b) designate persons or an existing structure within the institution to undertake the responsibilities of the OTT. Hockaday (2009) states that an OTT is that part of the institution responsible for commercialising institutionowned IP through the core activities of attracting and assessing invention disclosures; identifying ways and means of IP protection; making decisions on exploitation of IP such as licensing and or spin-out company formation. Table 1 attempt to elaborate when each commercialisation route should be considered, together with advantages and disadvantages of the licensing and spin-out companies. From Table 1 it is clear that there are possible circumstances that call for either licensing or spin-out company formation as methods for commercialisation. The OTT should therefore be prepared to understand spin-out company formation when circumstances arise allowing for establishing new companies that are formed specifically to develop and exploit IP. These new business ventures are called spin-out companies (Cook, 2007). In essence, a spin-out is 
a new company that is formed: (1) by individuals who were former employees of a parent organisation, (2) a core technology that is transferred from the parent organisation (Steffensen, Rogers \& Speakman, 1999).

Table 1: Selected Aspects Relating to Commercialisation Routes (licensing and spin-out company).

\begin{tabular}{|c|c|c|c|}
\hline $\begin{array}{l}\text { Commercialization } \\
\text { Route }\end{array}$ & When to consider & Advantage & Disadvantage \\
\hline Licensing & $\begin{array}{l}\text { Evolutionary technology/ } \\
\text { incremental Established markets } \\
\text { and suppliers }\end{array}$ & $\begin{array}{l}\text { Once the transaction is } \\
\text { complete, less diversion } \\
\text { Upfront and early revenue }\end{array}$ & $\begin{array}{l}\text { Return can be long- } \\
\text { term }\end{array}$ \\
\hline Spi & $\begin{array}{l}\text { The technology needs further } \\
\text { development to obtain "full" } \\
\text { value } \\
\text { New markets and/or more space } \\
\text { for new suppliers } \\
\text { More capital/more risk }\end{array}$ & $\begin{array}{l}\text { Longer term, intimate } \\
\text { involvement } \\
\text { Potential for greater return } \\
\begin{array}{l}\text { Allows further } \\
\text { development of early IP } \\
\text { before "sale" }\end{array}\end{array}$ & $\begin{array}{l}\text { Time and resource } \\
\text { intensive } \\
\text { No early money } \\
\text { High risk }\end{array}$ \\
\hline
\end{tabular}

Source: University of Southampton (2014).

The process for spin-out creation within the publicly financed research institutions is usually facilitated by OTTs. Pirnay, Surlemont and Nlemvo, (2003) further extended the spin-out company definition to "new firms created to exploit commercially some knowledge, technology or research results developed within a university". They also indicate the following as being main characteristics: new companies; created from universities; exploit knowledge produced by academic activities; a profit-making perspective. Pattnaik and Pandey, (2014) posit that, spin-out company characteristics are as follows: Firstly the parent organisation from which the innovation emerges has to be a university or academic institution, secondly the output that is a university spin-out has to be a separate legal entity which is not an extension or controlled body of the university, thirdly the new entity has to exploit knowledge produced from academic activities or academic pursuits and fourthly the spin-out company should be aimed at profit generation and commercialisation of technology.

International historical trends show that spin-out company creation by OTTs has been on the rise (Djokovic \& Souitaris, 2006). "In the United States of America (US), the annual number of spin-outs increased from 202 in 1996 and to 424 in the year 2001. In the United Kingdom (UK), a sharp rise of spin-out creation between 1996 and 2001 has been reported from an average of 94.8 \% per year" (Djokovic and Souitaris, 2006). This rise in spin-out company formation suggests that OTTs internationally have considered this as a viable option for IP commercialisation. The assumption being that circumstances indicated on Table 1 had raised at the time Corsi and Prencipe, (2016) also make the same observation that publicly funded research institutions are choosing the creation of spin-out companies as a preferred route for commercialisation versus licensing whilst reflecting academic entrepreneurs as social capital. Academic/institutional entrepreneurship has somewhat become a trend due to publicly-financed research institutions such as universities have had increased difficulties in maintaining requisite funding levels (Lui and Dubinsky, 2000). In line with this academic/institutional entrepreneurship trend, spin-out companies have proven to be an important economic phenomenon (Di Gregorio and Shane, 2003).

Miranda et al. (2017) define academic entrepreneurship as the process by which an individual or group of individuals are linked through their work to a university or research centre by using knowledge created in their research to set up spin-out companies. They emphasise the importance of these spin-out companies as an instrument that contributes to the generation of businesses, the creation of jobs and maintaining the balance of the economic system, as well as having a positive influence on innovative processes. In the process reflecting that spin-out creation phenomenon as part of academic entrepreneurship, had help assist in establishing an estimated total of 1110 spin-off in Spain by 2012. From this, an observation can be made that academic entrepreneurship as a phenomenon can assist in playing a role in spin-out company creation. In an attempt to understand the spin-out company formation process, a number of consulted texts reveal certain models. Ndonzuau, Pirnay and Surlemont (2002) indicate that spin-outs are created over four stages. These 
being: "(i) generation of business ideas from research, (ii) new venture projects out of ideas, (iii) launching of spin-out from projects and (iv), strengthening the creation of economic value by the spin-out company."

Furthermore, Roberts and Malone (1996) identified four principal entities involved in the spin-off process:" $(\mathrm{i})$ the technology originator, the person or organisation that brings the technology from basic research through the stages of the innovation-development process to the point at which the transfer of technology can begin, (ii) the parent organisation in which the R\&D is conducted by the technology originator, and that assists or restricts the spin-off process by controlling the intellectual property rights to the technology, such as through the parent organization's technology licensing office, (iii) the entrepreneur (or the entrepreneurial team), who takes the technology created by the originator and attempts to create a new business venture cantered on the technology, and (iv) the venture investor, who often represents a venture capital organisation that provides funding for the new company in return for partial equity ownership in the new company." Rasmussen, (2006) takes an entrepreneurial process view in approaching the context of spin-out company creation. Emphasis is made on the individual(s), the opportunity, the context, and the process over time as reflected in Figure 1.

\section{Figure 1: The Entrepreneurial Process of Spin-Out Company Creation}
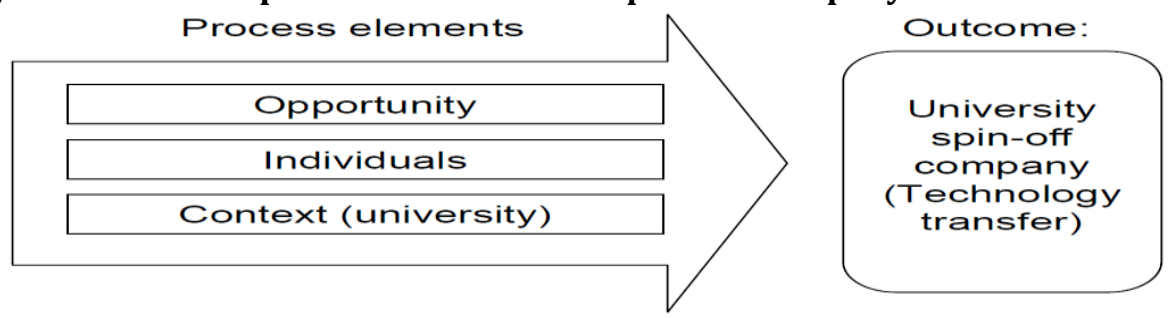

Source: Rasmussen, (2006)

In dealing with the context related to an entrepreneurial process for spin-out company formation, Rasmussen, (2006) elaborates on three perspectives influencing the spin-off process as follows: Firstly, the development process of a technology or business opportunity from being an idea to become an independent new venture. Secondly, the role of the individual (s) or entrepreneur (s) in the business development processes. Thirdly, the role of the context and how this influences the venturing process. Ultimately stating that within the university spin-off literature, special emphasis has been on the institutional context within a university and how this setting influences the business development process. Elpida et al. (2010) reconcile spin-out creation models as explained above (such as the entrepreneurial process model and the four-stage model of Ndonzuau, Pirnay and Surlemont, (2002). A further model is reviewed such as the Universidad Politecnica de Valencia (UPV) spin-out creation model. Stating that "on this model, the spin-off generation process is viewed as a process driven by the interaction of three elements: the entrepreneurs, the opportunity and the resources. These three elements at the first awareness or 'embryo' stage need to be combined by the entrepreneur's mind to create the fertile seeds of new ideas. These seeds are accumulated to a pre-incubator phase to concrete concepts, configuring the Cells of Opportunities (Coo)." From the models discussed above, Elpida et al. (2010) introduce their own model which integrates the above aspects of the entrepreneurial view and stages involved.

At the centre of the model being the entrepreneurial core however what gets introduced is the elements of the operational environment (available human capital, government policies and regulatory framework) and supportive structures (sources of capital and bridging institutions). Wnuk and Mazurkiewicz (2012), take a view of the spin-out creation process being either a downstream or an upstream model. The downstream model relates to four (4) stages that are: invention, incubation, seed-up and start-up. Stage one consists of the identification, assessment and protection of technologies with commercial potential. Stage two being the stage where business plans are drafted. The third stage being the phase of seeking business advice and initials seed funding. Stage four being the start-up phase entailing financial support for the venture to be formally incorporated, and spin-off startup process undertaken by means of prototyping, business models and markets validated. The downstream model on the other hand entails a reverse development from sales and services to innovation creation. This can be regarded as the opposite of the downstream model. In this model 
the spin-out company is created with no core propriety technology on, so the company is launched to generate revenue for the development of internal research and development (R\&D) infrastructure, which will then lead to new marketable inventions. In recent times, Berbegal-Mirabent et al. (2015) looked at factors that explain the creation of university spin-out companies by focusing on mechanisms that technology transfer offices (TTOs) and universities employ. These mechanisms include technology transfer activities that support spin-outs, normative frameworks, support infrastructures such as business incubators and science parks.

Finally, TTO staff's specialist technical skills assessment of the models involved in spin-out company creation as discussed by the authors above (Roberts and Malone, 1996; Ndonzuau, Pirnay \& Surlemont, 2002; Pirnay et al., 2003; Rasmussen, 2006; Wnuk \& Mazurkiewicz, 2012; Berbegal-Mirabent et al., 2015), it becomes clear that spin-out formation is a multi-variable aspect and can be complex to understand. A deeper look at the text of these authors mentioned above reveals that there are perhaps in one way or the other resources involved in spin-out company creation. For instance, Elpida et al. (2010) mention the human capital resource and financial resource in the operational environment and supportive structures respectively. Wnuk and Mazurkiewicz (2012), makes reference to financial resources in the form of seed funding on stage three and venture capital in stage four of their spin-out creation model. They also identify technological resources being central in their upstream and downstream model. Berbegal-Mirabent et al. (2015) deal with the aspect of physical resources in the form of support business incubators and science parks. Given that resources were identified as a pattern that seems to be common in the discourse of spin-out creation, an approach of visiting the resource-based view (RBV) theory of the firm was done starting from its pioneer Wernerfelt, (1984) to date.

\section{Literature Review}

Defining the Spin-Out Company: The literature reviewed in this study was based on understanding the Resource-Based View (RBV) theory in establishing factors that could influence the successful creation of spinout companies by publicly financed R\&D institutions. The spin-out companies considered were those created through the facilitation of a technology transfer office (TTO) in a publicly financed R\&D institution. As a first point, spin-out Company working definition had to be established. This was done by looking at several authors that made attempts to define the concept of a spin-out company within the context of publicly funded R\&D (Pirnay et al., 2003; Borges and Fillion, 2013; Pattnaik and Pandey, 2014). In defining the concept, there appears to be a pattern which reflects that the definition of a spin-out company is sometimes interchangeably defined with other concepts such as spin-off companies or university start-ups or academic enterprises.

When using these definitions interchangeably, Pirnay et al. (2003) reconciled these aspects and developed a working definition for this multi-facet concept. In their paper titled toward a typology of University Spin-off, Pirnay et al. (2003) define spin-off companies as "new firms created to exploit commercially some knowledge, technology or research results developed within a university." Pattnaik and Pandey, (2014) have made their contribution to the academic spin-out company definition by stating that its characteristics are as follows: Firstly the parent organisation from which the innovation emerges has to be a university or academic institution, secondly the output that is a university spin-out has to be a separate legal entity which is not an extension or controlled body of the university, thirdly the new entity has to exploit knowledge produced from academic activities or academic pursuits and fourthly the spin-out company should be aimed at profit generation and commercialisation of technology.

\section{Theoretical Framework}

General Overview of RBV Theory: The Resource-Based View (RBV) theory examines the success of an organisation to gain a competitive advantage as a result of a bundle of resources that it owns (Wernerfelt, 1984). The concept of studying the firm as a set of a wide variety of resources dates as far back as Penrose (1959), when she stated that "a firm is more than an administrative unit; it is also a collection of productive resources the disposal of which between different users and over time is determined by administrative decision. When we regard the function of the private business firm from this point of view, the size of the firm is best gauged by some measure of the productive resources it employs." However, it was Wernerfelt (1984) 
who came up with the term research-based view (RBV) on his paper (A research-based-view of the firm). This paper researched more on the relationship between profitability and resources and furthermore how firms can manage their resource position over time. Wernerfelt (1984) further explored the usefulness of analysing firms from the resources side, rather than from the product side. In dealing with resources certain aspects were examined such as: looking at firms in terms of their resources, identifying the types of resources that can lead to profits which are higher, striking a balance between exploitation of existing resources and developing new ones and purchasing of a bundle of rare resources. Barney (1991) further contributed to the resource-based view theory by stating that in essence the RBV theory indicates that typical resources of a firm are assets, capabilities, organisational attributes, information and knowledge. In a way of consolidation, resources can be bundled as either tangible or intangible.

Once these resources are established only then can a firm/organisation create strategies to improve its competitive and sustained advantage, Barney (1991). Given the debate above, it becomes apparent that resources and capabilities etc. are of importance in understanding organisational outputs or more importantly how organisations use their resources and capabilities to achieve a competitive advantage. Amit and Schoemaker (1993) indicate by definition that resources are stocks of available factors that are owned or controlled by the firm, that are converted into final products or services. Capabilities, on the other hand, are a firm's capacity to deploy resources. This deployment can be in combination, using organisational processes, to produce the desired effect. This statement then makes it clear that there is a distinction between resources and capabilities. Grant, 1991 makes the distinction that although resources are the source of a firm's capabilities are the main source of its competitive advantage.

RBV Theory in Spin-Out Company Creation: Some of the relevant factors that could influence the successful creation of spin-out companies that were identified in this literature review taking into consideration RBV as discussed by several authors were: Venture capital, intellectual eminence, university policy and commercially oriented research were resources discussed by Di Gregorio \& Shane (2003) in their article "why do some universities generate more start-ups than others?" Research and Development (R\&D) revenue, faculty quality, university patents, technology transfer office and venture capital munificence were the five particular resource sets discussed by Powers \& McDougall (2005). Lockett et al. (2003) assessed the impact of university resources and routines/capabilities on the creation of spin-out companies, these being intellectual property protection, the business development capabilities of technology transfer offices and the royalty regime of the university. Whilst Markman et al. (2005) looked at the type of organisational structure as a resource in influencing spin-out creation. Seemingly Powers \& McDougall (2005) touch on venture capital aspects. Finally, Walter, Auer and Ritter (2006) looked at the impact of network capability (NC), defined as a firm's ability to develop and utilize inter-organisational relationships, and entrepreneurial orientation (EO) on organisational performance.

From the numerous list of relevant spin-out creation success factors discussed, it was clear that a consolidated list had to be created to reduce the resources considered to be success factors for spin-out company creation into a workable number. A consolidation of similar factors that featured widely was done to reduce them to the prominent list cited on the study of Gómez-Gras et al. (2006), who studied and summarised these resources relating to spin-out company creation from a RBV perspective as follows: intellectual eminence/faculty quality, patent importance, total research income/expenditures, expenditure on IP protection, formal venture capital available at the university's geographical area, capability to access to external finance, industry funding of university research/revenues, licensing/technology transfer policies and strategies, OTT archetype, university-affiliated incubators, university venture capital funds, experience/age of OTT, number of OTT staff and business development capabilities including NC and EO by (Walter et al., 2006).

Success Factors for Creating Spin-Out Companies: Given that a number of authors as indicated above in the literature had some similarities and in some instances had differences, it was deemed fit to place these factors into a more structured list. A two (2) step approach was used in formulating a final list of fifteen (15) success factors by firstly combining similar factors for a relevant meaning and secondly discarding nonsignificant factors. 
Researcher's Quality: This factor was a combination of the wording "intellectual eminence" and "faculty quality." From a South African publicly financed R\&D perspective it would be relevant not to restrict the study to university faculty but rather include science councils of which then faculty quality would not apply. By not restricting the definition to university faculty, research/researcher quality would be deemed fit to accommodate science councils. Also, taking into consideration that the research is conducted by researchers, therefore it would be necessary to understand the researchers behind the research. The quality of research and the researcher would cover the "faculty quality" outside of a university setting.

Intellectual Property (IP) Strength: This factor was derived from the patent importance factor as listed by Gómez-Gras et al. (2006) who discarded this factor stating that "Powers \& McDougall (2005) did not prove patent importance to be predictive of a number of start-ups". However, what seems to be not looked at was intellectual property as a whole which extends beyond patents to include trademarks, design rights, trade secrets/know-how, copyright etc. The assumption here is being that there would most likely be value in assessing the IP strength through including other types of IP. In the South African publicly finance R\&D context, taking into consideration the IPR-PFRD Act, it is necessary to note that this defines IP as "any creation of the mind that is capable of being protected by law from use by any other person, whether in terms of South African or foreign intellectual property law and includes any rights in such creation, but excludes copyrighted works such as a thesis, dissertation, article, handbook or any other publication which, in the ordinary course of business, is associated with conventional academic work."

Research Income: This factor considered that total research income/expenditures could be ambiguous and therefore the expenditure part was discarded to only focus on the income side. This would take into consideration that any income that a research project brings would have to result in its expenditure. Publicly financed R\&D institutions in SA are involved in a variety of contract Research and Development (R\&D). As per Gómez-Gras et al. (2006) the following emerges on research income. Powers \& McDougall (2005) found industry R\&D revenues, was positively predictive of both the number of start-ups formed and the number of initial public offering (IPO) licenses. Di Gregorio \& Shane (2003) don't find adequate support for the argument that industry funding of university research makes start-up activity more likely.

Intellectual Property Protection Funding: Given the case that in this study protectable IP will be looked at as a whole, its expenditure on protection would be necessary to be examined. Liu and Jiang (2016) investigate the effects of bank equity connections and intellectual property protection on enterprises' innovation behavior, and the regulating effect of intellectual property protection on the relationship between bank equity connections and innovation. Stating that bank equity connections and intellectual property protection improves innovation performance.

Venture Capital Funding: This factor is derived from the factor titled "formal venture capital funding available at the university's geographical area" as stated by Gómez-Gras et al. (2006). The element regarding the geographical area is discarded given that in South Africa it is observed that venture capital funding is not necessarily geographically bound in provinces but spread across Southern Africa as indicated on (www.savca.co.za) where they state that they promote transactional venture capital and private equity investments throughout Southern Africa. The element regarding university was also discarded due to the study being targeted at publicly financed R\&D institutions which include science councils. For example, Powers \& McDougall (2005) indicate that there is evidence that universities situated in areas with abundant venture capital investment formed a greater number of start-ups. From this perspective, it would be interesting to find out the South African perspective.

Capability to Access to Third Stream Income: This factor is based on the combination of the factors "capability to access external finance and "industry funding of university research/revenues" Gómez-Gras et al. (2006). In a university context, the income generated from sources other than government subsidies and tuition or student fees are generally referred to as third steam income (MacGregor, 2008). With the understanding that from a RBV perspectives, this capability would be existing in higher education institution's TTO or science councils for that matter. 
Technology Transfer Policies and Strategies: This factor is derived from the factor "licensing/technology transfer policies and strategies." The licensing component was excluded in the definition as in publicly financed R\&D institutions licensing could be a policy or a strategy in itself. Roberts and Malone (1996) deals with these aspects extensively and reflects the importance of policies and processes in the spin-out company creation process. Within the technology stations are high-tech equipment forming part of the infrastructure (www.tia.org.za/tech-stations).

Technology Transfer Structure: This factor was defined by taking into consideration that a technology transfer office either exists as departments within institutions or subsidiary companies. Importantly reflecting that a subsidiary TTO the ability to commercially exploit the opportunities more efficiently than inside the university setting. The OTT framework was as published by the National Intellectual Property Management Office (NIPMO) was a document of consultation as which deals with factors such as OTT staff, model, structure, vision and mission). Regarding the revenue model, the OTT framework reflects contract R\&D, Licensing (royalty revenue) and Start-up activity. This indicates that potential focus on start-up activity could lead to a propensity for spin-out company creation. Regarding vision and mission, there is a strong emphasis on the publicly financed R\&D organisation (university or science council) vision and mission and its alignment to the TTO. Taking into consideration the IPR-PFRD Act objective relating to ensuring that IP emanating from publicly financed R\&D is identified, protected, utilised and commercialised for the benefit of the people of the Republic of South Africa.

Access to Incubation Facilities: This factor took into consideration that most incubators in South Africa are mainly managed by the Department of Trade and Industry and are not necessarily linked specifically to individual universities although they could potentially benefit these incubators are found on (www.seda.org.za).

Entrepreneurial Orientation: This factor is influenced by the Walter et al. 2005 study which indicates that entrepreneurial orientation has positive effects on spin-off performance. Finding that it has a highly significant directs effect on the realization of competitive advantages. Concluding that it can preserve a spinoff's existence attract customers, and improve the organization's reputation as a competent technology provider. Ultimately this talks to the role of the individual(s) or entrepreneur(s) in the business development process of a spin-out as indicated by Rasmussen, (2006).

Business Development Capability of TTO Staff: Business development capabilities of TTO staff are identified as important by the NIPMO OTT framework and are included for that reason. These business development capabilities being technology assessment, drafting market reports, analysing market structures that the institutional IP can be licensed to, reviewing industry value chains, drafting commercial strategies for disclosed inventions, business plans for IP with spin-out potential and creating spin-out companies.

Access to Technology Stations: Technology stations have a presence in a South African publicly financed institution in order to assist in the commercialisation of research. According to the Technology Innovation Agency (TIA) website technology Stations support industry in diversified sectors, ranging from agroprocessing, chemicals, clothing \& textile, automotive industry and tooling Sector. These centres are worldclass service providers of Engineering services to Technology based SME's, which are provided by technical experts from various universities and industry, with the requisite skills and expertise. The assumption here that publicly financed R\&D institutions could have access to technology stations as a physical resource that could potentially assist with the process of spin-out company creation.

Type of Technology: Assessing whether the technology is based on radical (different from prior solutions) or incremental (makes a relatively minor change from existing practices) Schilling, 2010. Furthermore, Clarysse et al. (2005) contribute to the literature on university spin-offs by exploring how different characteristics in the technological knowledge base at start-up influence spin-off performance. This is done by them looking at technologies under the categories relating to the scope of technology, the newness of the technology, tacitness of the technology and relatedness of the technological knowledge. Whilst Renault et al. (2016) emphasizes that the technological resources category refers to the basic skills and technologies specific to each company. Indicating that technology-based spin-out companies has a variety in their degree 
of innovation and technological scope, the nature/intensity of their R\&D activities and positioning in the product development cycle.

Stage of Development of the Technology: Assessing if it is early or late stage technology. One way of assessing this is by looking at Renault et al. (2016) who cited the stage of technology in relation to the type of product/service the spin-out company provides. For example, service-oriented forms tend to utilise customised consulting and R\&D services stage technology. Whilst product oriented firms tend to utilise technologies at a mature stage and tested in the market being part of the production.

Number of OTT Staff: Regarding staff, the OTT framework examines the staff component of the technology transfer office elements such as skills set, staff size and the role these individuals play in the TTO. Inference can be made that staff can potentially play a vital role in the spin-out creation process should they be aligned to tie objective.

Linking RBV Resources to Success Factor for Spin-Out Company Creation: Different authors have categorised RBV resources differently, although somewhat related (Barney, 1991; Landry, Amara, Rherrad, 2006; Renault et al., 2016). Researchers using a resource-based view of the firm have, in general, grouped resources into the five (5) categories: financial, physical, human capital, organisational and technological. Table 2 links the factors discussed in section 2.3 to the identified resource categories. When assessing success factors there has to be an indication of whether these are influenced by which resource categories. A model was created in order to systematically understand the link between the RBV theory and the potential success factors for spin-out creation. Four elements were taken into consideration i.e. (the spin-out company type, the type of publicly financed R\&D institution, the RBV resource and the success factor). Figure 2 below attempts to depict this concept graphically:

Table 2: Linking the Selected Fifteen (15) Success Factor to the Five (5) RBV Resource Categories

\begin{tabular}{ll}
\hline Resource Category & Success Factor \\
\hline Financial & Research income \\
& Venture capital funding \\
& IP protection funding \\
& Researcher quality \\
Capability to access to third stream income & Business development capability of OTT staff \\
& Technology transfer policies and strategies \\
Trganisational & Technology transfer structure \\
& Institutional Eminence \\
& Access to incubation or science park facilities \\
Physical & Access to technology station \\
& Intellectual property (IP) strength \\
Technological & Type of technology \\
& Stage of development of the technology \\
\hline
\end{tabular}

Source: Authors own table (interpretation of linking success factors to RBV) considering the following references (Barney, 1991; Landry, Amara, Rherrad, 2006; Renault et al., 2016). 
Figure 2: Model for Success Factors that Influence Spin-Out Creation (RBV perspective)

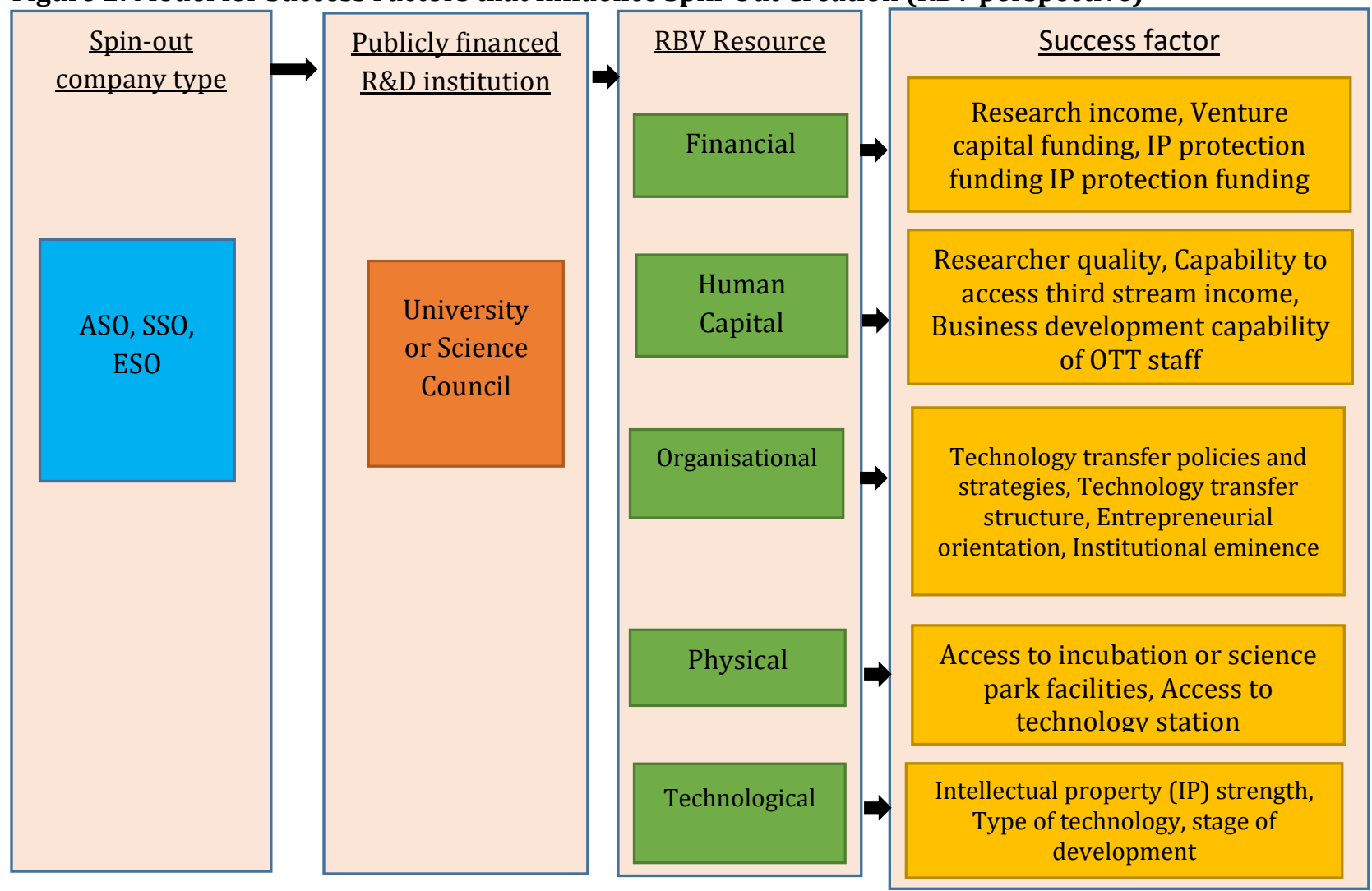

Source: Authors own figure (interpretation of linking success factors to RBV). When taking into consideration the model above, it was relevant to place the type of a spin-out company at the beginning of the chain. In this instance contextualising if the spin-out company is an Academic Spin-offs (ASO), Student SpinOffs" (SSO) or Entrepreneurial Spin-Offs (ESO).

\section{Research Methodology}

Research Design: The study utilised a mixed methods research approach (both quantitative and qualitative). The majority of the questions were closed-ended (to probe quantitative data) and few open-ended (to probe the qualitative data).

Population and Sampling: The main sampling approach was non-probability sampling. This approach was chosen because it provided a range of alternative techniques to select samples based on the subjective judgement of the researcher, Saunders, Lewis and Thornhill, (2009). Non-probability sampling can be categorised into quota, purposive, self-selection, convenience and snowball sampling. For this study a purposive sample was selected. The target population size was 49 and this also part of the sample. The study therefore considered this as a census where the size of the population is equal to the sample size. This form of the sample is often used when working with very small samples. Furthermore, this method involved identifying and selecting individuals or groups of individuals that were knowledgeable or experienced (Cresswell and Plano Clark, 2007). The process for sampling step by step is as follows: (a) the target population was defined (b) the sample was determined and (c) the final sample was sent out questions.

Data Collection Approach: Institutions that were involved in spin-out company creation. The respondents were given a week turn-around time to respond to the researcher. Of the 49 distributed, 17 were returned.

Questionnaire: The data collection instrument consisted of questions (open-ended and close-ended) assessing different aspects relating to respondents deemed success factors in the spin-out company creations 
process. The questionnaire structured for self-administration. The questionnaire was designed by means of first laying out the demographical data of the respondents, followed by having sections dealing with the categories relating to RBV factors that played a role in creation of the spin-out company (close-ended) and lastly by having a section asking opinions of the RBV categories that played a role in the creation of spin-out companies. The main variables being the RBV factors in spin-out company creation.

Data Analysis: The study used descriptive statistics rather than inferential statistics in order to describe the facts through graphs and tables.

\section{Results and Discussion}

Financial Resources: The data on this study reflected that financial resources as a whole do play an import role in the creation of spin-out companies as indicated in the figure below:

\section{Figure 3: Role Played by Financial Resources}

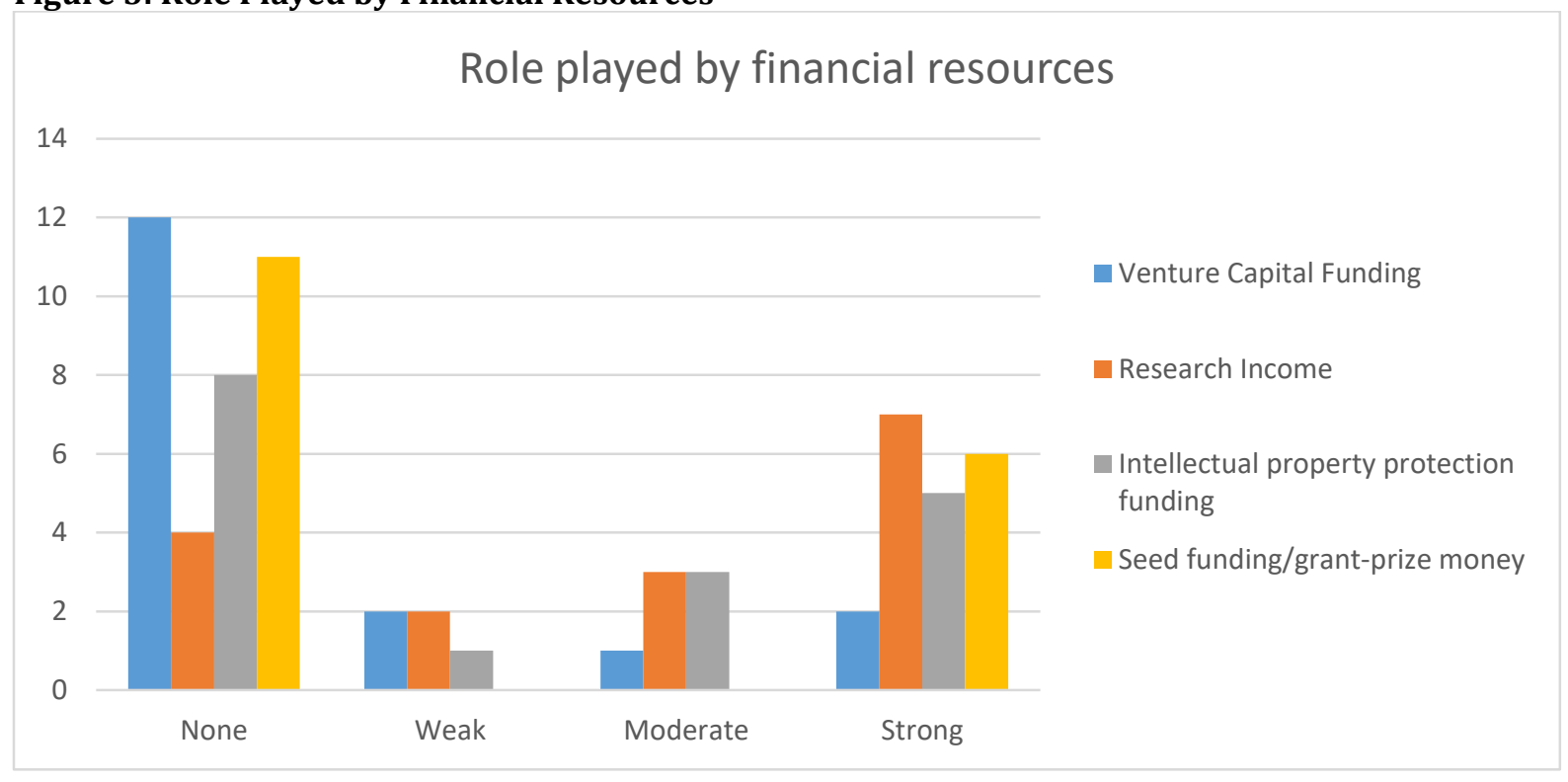

This is consistent with Landry et al. (2006) who found in general that the likelihood of spin-out company creation increases by the availability of financial resources. Landry et al. (2006) however make a distinction from the source of funding i.e. grant funding vs. private sector funding. Indicating that grant-funded R\&D can have a positive effect on launching spin-outs for example. This thesis however did not identify aspects such as by Di Gregorio \& Shane (2003) who on the one hand indicate from a financial resources perspective that types of private equity (e.g. angel capital) might influence start-up activity but on the other hand the amount of formal venture capital available in a particular location has no significant effect on spin-outs once university technology production is measured. This is a reflection of the diverse nature of this resource category. It can be concluded that the role that some of the individual financial resources played in the creation of spin-out companies is reflected on two opposite ends. On the one hand, some respondents felt that for example venture capital funding played no role in the creation of spin-out companies while a few felt it did play a role and a very strong role for that matter. Wnuk and Adam (2012) identified the importance of financial resources by placing them on stage three (seed funding) and stage four (venture capital) in their spin-out creation model. From the opinions of the respondents, the identified financial resources are important in spin-out company creation in that they are perceived to be third after scientists' availability, and technology strength. Most importantly, funding can assist to develop the market for the opportunity. In the absence of financial resources, the appetite to spin-out the technology would be low. In addition to technology development funding, instruments such as seed funding were made available, albeit that the criteria differed from opportunity to opportunity. 
Research Income: Research income played the most important role of all the financial resources. Powers \& McDougall (2005) found industry R\&D revenues (which for the purpose of this research has been termed research income), was positively predictive of the number of spin-outs formed.

Venture Capital Funding: This factor played the least important role in spin-out company creation. It is important to note that Powers \& McDougall (2005) indicated that there is evidence that universities situated in areas with abundant venture capital (VC) investment formed a greater number of start-ups. The cause for this result could be related to the observation that VC funding is minimal in SA and most probably in its infancy compared to established markets such as America and Europe.

IP Protection Funding: The results of this study place IP protection funding to be the second least important resource which can then be not that much in line with Lockett et al. (2003) who found expenditure on IP protection to be consistently significant in the creation of university spin-offs that attract external equity finance.

Seed Funding/Grant Prize Money: Interestingly it is worth noting that seed funding/grant-prize money was not a factor or resource stated upfront on the questionnaire but rather it emerged on the "other" section and formulated as a theme. More importantly this factor or resource emerged as the second most contributing aspect in this process. This could suggest that this is an SA unique phenomenon, given that over the past years institutions such as the innovation hub have been running competitions linked to prize money with the aim of developing start-ups (www.theinnovationhub.com). From the opinions of the respondents it seems that there needs to be a distinction between two broad categories of financial requirements namely: technology development funding \& new venture creation funding. Without adequate technology development funding, new venture creation funding would not even have been a prospect. Access to research funding during the background research, and access to seed funding for the spin-out process, makes it possible to explore the commercial viability of the invention by taking the technology from lab prototype to early product, can make it possible for spin-out companies to access third-party funding. Ultimately financial resources can be considered the go/no-go in determining the decision to spin-out even if all other requirements were in place. In some instances, spin-out companies can have the ability to return research funding to the organisation and this factor can influence somewhat the decision on whether to spin out, or enter into a license.

Human Capital Resources: Firstly, on the issue of assessing human capital specifically "researcher quality", Powers \& McDougall (2005) indicate that this is a critical human capital resource for the development of sophisticated, cutting-edge technologies. Going even further to state that if the publicly financed R\&D institution acquires it over time this becomes likely a source of competitive advantage. This is fundamentally what the RBV theory is about as defined by Barney (1991). Consistent with the literature, the findings of this study reveal that "researcher quality" plays the strongest role of all the human capital factors that were being reviewed. Secondly, on the issue of "business development capability of TTO staff", Locket et al. (2003) indicates the importance of a university having appropriately experienced staff in a technology transfer office to perform the function of opportunity recognition. The data on the study suggests that this function varies in the role it plays as a human capital resource across the lines of being weak to strong. Powers \& McDougall (2005) also affirm that as TTOs gain experience, they are more willing to consider equity in start-up companies. What is important to note is that during spin-out company formation, multiple personnel from different roles in the publicly financed institution can be involved. These key human capital resources can either be in the publicly financed R\&D institution or external. They can perform a wide variety of functions such as technical support, new IP generation, and marketing of the technology. In some cases, the combination of TTO staff with researchers being involved in spin-outs can allow researchers to learn the commercialisation aspects together with TTO staff, as a business case had to be developed. The themes based on the respondent's opinions are reflected below: 
Table 3: Human Capital Resources Themes

\section{Human Capital}

Resources Themes

Internal facilitators

Internally, experienced facilitators can make it possible to coordinate the spin-out company creation process.

These facilitators could be personnel in the organisation such as Vice Chancellor's sitting on the board or technology transfer professionals playing a surrogate entrepreneur role

Researchers and Other personnel that could be involved in the creation of the spin-out company are academics the researchers such as academics and students (especially postgrad) which form the core of the R\&D team. This can allow for continued R\&D and subsequently lead to improvements to and new technologies to be licensed further to the spin out. As a whole, access to high-talent human capital was instrumental to successfully spinning out the technology

TTO staff Respondents seem to comment that it is evident that the skills within the TTO can enable the formulation of the business case of which researchers would not be able on their own to package the opportunity in a manner that the case could be made for a new venture. It is key that in their involvement, the personnel such as the TTO staff are empowered to make decisions and should get very involved in the detail of the business, particularly through the difficult start-up period

External Externally, entrepreneurs can be roped in who have the skill to start and run a entrepreneurs business and act as CEO. These individuals are extremely important. There should be an entrepreneurial champion as such. Entrepreneur in resident programs can assist in this regard as a pool of entrepreneurial resources externally.

Source: Author's Concept

Organisational Resources: Roberts et al. (1996) indicated the importance of technology transfer policies and strategies together with structures in the spin-out company creation process. Reflecting on how the change on or the other aspect can alter the dynamics associated with the spin-out company creation process either for the positive or the negative. An interesting finding is made on this issue around organisational resources which is that the highest impact can be made by combining all the four (4) organisational resources identified for this study i.e. technology transfer policies, technology transfer structure, entrepreneurial orientation and institutional prestige. On the other hand, it is to be noted that technology transfer policy as a stand-alone organisational resource could influence the creation of spin-out companies. But what is critical is to note that the combination of technology transfer policy and structure play the most important role according to the respondents in this study. When assessing the element of institutional prestige, Di Gregorio \& Shane (2003) argues that institutional reputation makes it easier for researchers from more eminent universities to start companies to exploit their inventions than researchers from less eminent universities for example when it comes to the aspect of entrepreneurial orientation, it found that it is the second most important stand-alone resource.

Technology Transfer Policies and Strategies: These played the most important role in spin-out company creation. From RBV perspective policies and structures could be related to capabilities i.e. a firm's capacity to deploy resources (this deployment can be in combination, using organisational processes, to produce the desired effect). It should be noted that in the questionnaire there was no specificity on what the technology transfer policies and strategies are in depth. So, depending on the respondent's positive/negative experience then can this be understood? Under the assumption that the thinking upon responding was a positive policy/strategy in mind, then these results are consistent with for example the findings of Di Gregorio \& Shane (2003) who for example found that a positive policy such as allowing for inventors' share of royalties and a willingness to make equity investments in start-up companies increase spin-out company creation.

Technology Transfer Structure: Technology transfer structure played the least important role on par with institutional prestige, but not to say that it did not play a significant role because it is fairly strong. To a certain extent element of this resource are in line with Markman et al. (2005) who found that the for-profit 
technology transfer office structure played a positive role in the transfer of new technology via new venture formation. This is of course with the assumption that this was the structure considered. In the SA context, as per the OTT framework by NIPMO, it is worth noting that other structures exist such as department/office within the institution, a subsidiary company of the institution or regional office.

Entrepreneurial Orientation: This factor reflects as the second most important factor in the spin-out company creation process consistent with Walter et al. (2006).

Institutional Eminence: Least important and contradictory to Di Gregorio \& Shane (2003) who found that more eminent universities have greater start-up activity than other universities.

Physical Resources: Physical resources identified in the literature review seem to not play much of a strong role in the spin-out company creation process. This prompted to visit more literature and it was found that other authors seem to suggest that this is the case. For example, the research of Clarysse, Wright, Lockett, Van de Velde and Vohora (2005) shows that the incubator model results in fewer spin-outs. What is of interest is that this thesis found that a category of "lab facilities" to be of great importance. To quote directly from a respondent: "Availability of facilities to manufacture the product \& test the market directly from an R\&D institution pre-incorporation of a new venture." Laboratory space and equipment use of biotech laboratory and analytical equipment. The data also indicated that a combination of incubators and science parks play just as an important of a role as lab facilities with both coming in at $25 \%$ each. In the opinion section, some comments were made around the issue of incubation being either internal or external. And some suggestions were made for example on how the incubator inside the organisation can make it possible to initially incubate the technology in a research lab. This can allow for the spin-out company to grow in a very cost-effective way, and close to the university staff involved in the spin-out. Also, internal incubation could include mentoring and business coaching. Finally, physical resources as a whole help to de-risk the technology, they supply supportive testing/development capacity for the start-up and help avoid the need for early capital expenditure. Without the physical resources, it could be difficult to make a success out of a spin-out company. On the other hand, however it is important to note a respondent indicated that physical resources were not important at all to their spin-out company creation.

Technological Resources: The technological resource category in this study strongly suggests that the combination of intellectual property (IP) strength, stage of development of the technology and type of technology play an important role. Furthermore, this combination is regarded as a strong indicator of whether spin-out company creation will occur or not as shown. It is to be noted that it scored the highest percentage out of all the studied resource categories, suggesting that successful spin-out company creation is perhaps stronger and mostly influenced by the combination of resources in the technological category. The opinions made on this section also went steps further to clarify which types of technology are likely to influence this process and which ones don't. What was not conclusive was the issue of IP strength as a standalone resource. From the respondents, two extreme views emerged. On the one hand, some respondents emphasised the importance of IP strength while some respondents indicated that the spin-out did not depend on IP but rather what is important here is getting the product to market. It is important to note that "Powers \& McDougall (2005) did not prove patent importance to be predictive of a number of start-ups" as stated by the Gómez-Gras et al. 2006. Ultimately the technological resources should have elements of quality, credibility and be of good status. Even to the extent that comments were made indicating that without technological resources there would have been no spin-out company in the first place. This seems to be consistent with the results of this study reflecting the combination of technological resources. 
Figure 4: Important Technological Resources that Played a Role in Spin-Out Company Creation

\title{
Technological resources of importance
}

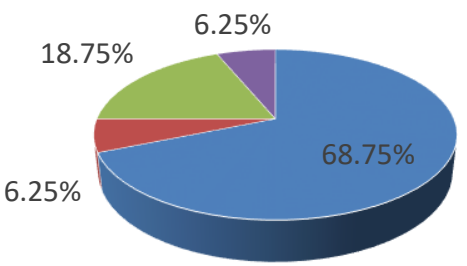

\author{
- Intellectual property (IP) strength/stage of development of the technology/type of technology \\ - Intellectual property (IP) strength/stage of development \\ - Intellectual property (IP) strength/type of technology \\ - stage of development/type of technology
}

\section{Conclusion}

The findings in this study about success factors for spin-out company creation closely resemble the RBV theory approach to understanding spin-out company creation as per the literature reviewed. In some instances, it agreed with the literature reviewed and in some instances, it did not. The gaps that existed were identified. Some of the notable important finds are in connection with: All five resource categories i.e. (financial, physical, human capital, organisational and technological) through the sub-category factors do play a role (positive or negative) one way or the other in the process of spin-out company creation as indicated in section 4. Lab facilities within publicly financed R\&D institutions and their ability to help de-risk technology development. This is discussed in section 4 indicating that they supply supportive testing/development capacity for the start-up and help avoid the need for early capital expenditure. The highest indicator coming from the combination of technological resources (IP strength, stage of development of the technology and type of technology) as reflected in section 4.

Implications for Policy Makers and Technology Transfer Practitioners: With the advent of the IPR-PFRD Act's requirements of commercialisation and use, spin-out company creation is becoming more and more important. This study will allow for policymakers and technology transfer professionals, especially commercialisation practitioners to have a point of reference for this aspect (spin-out company creation) within the South African context.

Limitations: While this study provides useful insights into the successful creation of spin-out companies by publicly financed R\&D institutions, it is not without its limitations. A first potential shortcoming would relate to the resource category variables. For example, more variables could have been added to each resource categories, but this would have potentially caused an endless list, hence the category approach was chosen. This then provides an opportunity for further research on other potential RBV categories within this aspect of spin-out company creation. The research narrowly focused on resources and in some instances capabilities, but did not divulge deep into dynamic capabilities. No assessment was made on understanding the reconfiguration of resources within firms. This places an opportunity for further research. 


\section{References}

Amit, R. \& Schoemaker, P. J. H. (1933). Strategic Assets and Organizational Rent, Strategic Management Journal, 14(1), 33-46.

Barney, J. (1991). Firm resources and sustained competitive advantage, Journal of Management, 1, 99-120.

Berbegal-Mirabent, J., Ribeiro-Soriano, D. E. \& Gracia, J. L. S. (2015). Can a magic recipe foster university spinoff creation? Journal of Business Research, 68, 2272-2278.

Borges, C. \& Fillion, L. J. (2013). Spin-off Process and the Development of Academic Entrepreneur's Social Capital, Journal of Technology Management \& Innovation, 8, 21-34.

Clarysee, B., Wright, M., Lockett, A., Van De Velde, E. \& Vohora, A. (2005). Spinning out new ventures: a typology of incubation strategies from European research institutions, Journal of Business Venturing, 20, 183-216.

Cook, T. (2007). The Role of Technology Transfer Intermediaries in Commercializing Intellectual Property through Spinouts and Start-ups. In Intellectual Property Management in Health and Agricultural Innovation: A Handbook of Best Practices.

Corsi, C. \& Prencipe, A. (2016). Improving Innovation in University Spin-Offs. The Fostering Role of University and Region, Journal of Technology Management \& Innovation, 11, 13-21.

Creswell, J. (2007). Qualitative inquiry and Research Design: Choosing among Five Approaches (2nd ed). Thousand Oaks, CA: Sage.

Di Gregorio, D. \& Shane, S. (2003). Why do some universities generate more start-ups than others? Research Policy, 32, 209-227.

Djokovic, D. \& Souitaris, V. (2006). Spinouts from academic institutions: a literature review with suggestions for further research, Journal of technology transfer, 33, 225-247.

Elpida, S., Galanakis, K., Bakouros, L. \& Platias, S. (2010). The spin-off chain, Journal of Technology Management \& Innovation, 5, 52-68.

Gómez-Gras, J. M., Pastor-Ciurana, J. T., Galiana-Lapera, D., Mira-Solves, I. \& Verdú-Jover, A. T. (2006). indicators of academic entrepreneurship: monitoring determinants, start-up activity and wealth creation. global start project.

Intellectual Property Rights from Publicly Financed Research and Development. (2008:2).

Landry, R., Amara, N. \& Rherrad, I. (2006). Why are some university res0earchers more likely to create spinoffs than others? Evidence from Canadian universities, Research Policy, 35, 1599-1615.

Liu, S. \& Dubinsky, J. (2000). Institutional Entrepreneurship a panacea for universities-in-transition? European Journal of Marketing, 34, 11-12.

Locket, A., Wright, M. \& Franklin, S. (2003). Technology Transfer and Universities' Spin-Out Strategies. Small business economics, 20, 185-200.

Markman, G. D., Phan, P. H., Balkin, D. B. \& Gianiodis, P. T. (2005). Entrepreneurship and university-based technology transfer, Journal of Business Venturing, 20(2), 241-263.

Macgregor, K. (2008). South Africa: Third stream income a new priority (online).

Marinda, F. J., Chamorro-Mera, A. \& Rubio, S. (2017). Academic entrepreneurship in Spanish universities: an analysis of the determinants of entrepreneurial intention, European research on management and business economics, 23, 113-122.

Ndonzua, F., Pirnay, F. \& Surlemont, B. (2002). A Stage Model of Academic Spin-Off Creation, Technovation, 22, 281-289.

Pattnaik, P. N. \& Pandey, S. C. (2014). University Spinoffs: What, Why, and How? Technology Innovation Management Review, 12, 44-50.

Penrose, E. T. (1959). The Theory of the Growth of the Firm. New York, John Wiley.

Pirnay, F., Surlemont, B. \& Nlemvo, F. (2003). Toward a Typology of University Spin-offs, Small Business Economics, 21, 355-369.

Powers, J. B. \& Mcdougall, P. P. (2005). University start-up formation and technology licensing with firms that go public: a resource-based view of academic entrepreneurship, Journal of Business Venturing, 20, 291-311.

Rasmussen, E. (2006). Spin-off venture creation in a university context-An entrepreneurial process view", Research Gate.

Renault, T., DE Mello, J. M. C., Fonseca, M. V. D. \& Yates, S. (2016). A chip off the old block: Case studies of university influence on academic spin-offs, Science and public policy, 43, 594-600. 
Roberts, E. B. \& Malone, D. (1996). Policies and structures for spinning off new companies from research and development organizations. R\&D Management, 26, 17-48.

Saunders, M., Lewis, P. \& Thornhill, A. (2009). Research Methods for Business Students (5th ed). Harlow: FT Prentice Hall.

Schilling, M. (2010). Strategic Management of Technological Innovation. 3rd ed. International: McGraw-Hill.

South Africa. (2008). The Intellectual Property Rights from Publicly Financed Research and Development Act.

South African Venture Capital Association. (2016).

Steffensen, M. Rogers, E. M. \& Speakman, K. (1999). Spin-offs from research centres at a research university, Journal of business venturing, 15, 93-11.

Technology innovation agency website. (2016).

Uctu, R. \& Jafta, R. (2014). Spinning-off or licensing? The case of academic technology transfers at two South African universities. Industry and Higher Education Journal, 21, 127-141.

Walter, A., Auer, M. \& Ritter, T. (2006). The impact of network capabilities and entrepreneurial orientation on university spin-off performance, Journal of Business Venturing, 21, 541- 567.

Wernerfelt, B. (1984). A Resource-Based View of the Firm, Strategic Management Journal, 5, 171-180.

Wnuk, U. \& Mazurkiewicz, A. (2012). Research-based spin-off processes and models in a different economic context, Problemy Eksploatacji, 2, 177-192. 